\title{
Evaluation of Haematological and Reproductive Effect of Paracetamol (Acetaminophen) In Female Abino Rats
}

\author{
Oyedeji K.O ${ }^{1}$., Bolarinwa A.F ${ }^{2}$, Adabanija R.B. ${ }^{1}$ \\ ${ }^{I}$ Department of Physiology, Faculty of Basic Medical Sciences, Ladoke Akintola University of Technology, \\ P.M.B. 4000, Ogbomoso, Nigeria. \\ ${ }^{2}$ Department of Physiology, College of Medicine, University of Ibadan, Ibadan, Nigeria. \\ ${ }^{3}$ Department of Physiology, Ladoke Akintola University of Technology, Ogbomoso, Nigeria.
}

\begin{abstract}
The effect of oral administration of $7.5 \mathrm{mg} / \mathrm{kg}$ BW of paracetamol on haematological and reproductive parameters in female albino rats were investigated. The paracetamol was administered by gavage on daily basis for haematological study, but administered orally for 21 days for estrous cycle study.

Treatment of rats with $7.5 \mathrm{mg} / \mathrm{kg} B W$ of paracetamol caused insignificant ( $p>0.05)$ changes in the $R B C, P C V, H b, T W B C$, platelet, neutrophil, lymphocyte, eosinophil, monocyte and haematmetric indices (MCV, $M C H C, M C H)$ values relative to their respective controls.

Treatment of rats with paracetamol $(7.5 \mathrm{mg} / \mathrm{kg} \mathrm{BW})$ caused non-significant changes in the duration of all phases of estrous cycle relative to their respective controls.

These findings probably indicates that paracetamol has no deleterious effect on the blood chemistry and fertility of female albino rats.

Key words: Paracetamol, Red blood cell, Total white blood cell, Estrous cycle, Albino rats.
\end{abstract}

\section{Introduction}

Paracetamol is classified as a mild analgesic. It is commonly used for the relief of headaches and other minor aches and pains and is a major ingredient in numerous cold and flu remedies. In combination with opoid anlygesic, paracetamol can also be used in the management of more severe pain such as post-surgical pain and providing palliative care in advanced cancer patients (SIGN, 2008).

Paracetamol toxicity has been reported to be the foremost cause of acute liver failure in the Western world, and accounts for most drug overdoses in the United States, United Kingdom, Australia and New Zealand (Hawkins et. al., 2007). Its prolonged daily use has been reported to increase the risk of upper gastrointestinal complications such as stomach bleeding (Rodriguez and Hernandez-Diaz, 2000) and may cause kidney or liver damage (Michael et. al., 2007). Its derivative, nitroparacetamol, has been reported to exhibit anti-inflammatory and anti-noceptive activities in the rat (Al-Swayeh, 2000). The genotoxicity of paracetamol in mice and rats has also been reported (Hongslo et. al., 1993).

This study aims at investigating the effect of paracetamol on haematological and reproductive parameters in female albino rats.

\section{Experimental Animals}

\section{Materials And Methods}

Adult female albino rats weighing between $160 \mathrm{~g}$ and $180 \mathrm{~g}$ bred in the Animal House of Physiology Department, LAUTECH, Ogbomoso were used. They were housed under standard laboratory conditions with a 12 hours daylight cycle and had free access to feed and water; they were acclimatized to laboratory conditions for two weeks before the commencement of the experiments. All experiments were carried out in compliance with the recommendations of Helsinki's declaration on guiding principles on care and use of animals.

Drug

Paracetamol tablets (Emzoe Pharm Ltd) were bought from Jeopat pharmacy, Ogbomoso, Nigeria.

One thousand five hundred milligram $(1500 \mathrm{mg}$ ) of paracetamol were dissolved in $2000 \mathrm{ml}$ (2 litres) of distilled water to give a concentration of $0.75 \mathrm{mg} / \mathrm{ml}$.

The dosage of paracetamol administered in these studies was in accordance with those reported by Ucheya and Igweh (2006).

\section{Experimental Design}

(i) Haematological Study

Ten animals were randomly divided into two groups with each group consisting of five rats. The two groups of rats were subjected to the following oral treatments once a day for 30 days: 
Group I rats received $7.5 \mathrm{mg} / \mathrm{kg}$ BW of paracetamol

Group II rats received $0.5 \mathrm{ml}$ of distilled water as the control group.

Twenty-four hours (day 31) after the last dosing of the two groups, blood samples were collected.

\section{Collection of Blood Samples} analysis

Blood samples were collected through the medical cantus into EDTA bottles for haematological

\section{Determination of Haematological Parameters}

The red blood cells (RBC) and total white blood cells (TWBC) counts were determined by the improved Neubauer haemocytometer method. The haemoglobin $(\mathrm{Hb})$ concentration was determined according to Jain (1986), using the cyanomethaemoglobin method. The packed cell volume (PCV) was determined by the micro-haematocrit method according to Dacie and Lewis (1991). Schilling method of differential lecukocyte count was used to determine the distribution of the various white blood cells (Mitruka and Rawnsley, 1977). Mean corpuscular volume (MCV), mean corpuscular haemoglobin $(\mathrm{MCH})$ and mean corpuscular haemoglobin concentration (MCHC) were computed according to Jain (1986).

\section{(ii) Estrous Cycle Study}

Five matured female rats (160-180g) showing at least three regular 4-5 day cycles were used. Vaginal smears were examined microscopically every day at a constant interval of 10-11 a.m. for 21 days. The smears were classified into one of the phases of estrous cycle using the Papanicolaou's staining technique. The relative proportions of cells recognized were used to determine the phases of the estrous cycle according to Long and Evans (1922). The duration of the estrous cycle was determined. Then, the rats received $7.5 \mathrm{mg} / \mathrm{kg} \mathrm{BW}$ of paracetamol for another 21 days and vaginal smears were similarly evaluated during the administration of the paracetamol. In this study, the experimental animals also served as the control. The first 21 days served as the control days, while the last 21 days served as the treatment days.

Vaginal swab stick was used for smear collection from the vaginal lumen by introducing the swab stick gently into the vaginal and gently rotating it along the floor of the lateral walls of the vaginal. The swab stick was then rotated or smeared in duplicate on a microscope slide and the slide was stained using the Papanicolaou's staining technique.

\section{Statistical Analysis}

The mean and standard error of mean (S.E.M.) were calculated for all values. Comparisons between the control and the treated groups were done using the student's t-test. Differences were considered statistically significant at $\mathrm{p}<0.05$.

\section{Effect on Haematological Parameters}

\section{Results}

Table 1 shows the effect of treatment of rats for 30 days with paracetamol on haematological parameters.

Treatment of rats with paracetamol $(7.5 \mathrm{mg} / \mathrm{kg} \mathrm{BW})$ caused non-significant $(\mathrm{p}>0.05)$ changes in PCV, $\mathrm{Hb}, \mathrm{RBC}, \mathrm{MCV}, \mathrm{MCHC}, \mathrm{MCH}, \mathrm{TWBC}$, platelet, neutrophil, lymphocyte, eosinophil and monocyte values relative to their controls.

Table 1: Effect of treatment of rats with paracetamol $(7.5 \mathrm{mg} / \mathrm{kg} \mathrm{BW})$ on haematological parameters $(\mathrm{n}=5$,

\begin{tabular}{lll} 
& \multicolumn{1}{c}{$* \mathrm{P}<0.05)}$. & \\
\hline Parameters & Control & Treated \\
\hline $\mathrm{PCV}(\%)$ & $35.00 \pm 1.30$ & $37.40 \pm 1.63$ \\
$\mathrm{Hb}(\mathrm{g} / \mathrm{dl})$ & $11.52 \pm 0.50$ & $12.48 \pm 0.49$ \\
$\mathrm{RBC}\left(\times 10^{6} / \mu \mathrm{l}\right)$ & $6.11 \pm 0.33$ & $6.50 \pm 0.41$ \\
$\mathrm{MCV}(\mathrm{FL})$ & $57.54 \pm 1.32$ & $57.86 \pm 1.13$ \\
$\mathrm{MCHC}(\mathrm{g} / \mathrm{dl})$ & $32.90 \pm 0.18$ & $33.39 \pm 0.16$ \\
$\mathrm{MCH}(\mathrm{pg})$ & $18.93 \pm 0.41$ & $19.33 \pm 0.47$ \\
$\mathrm{TWBC}\left(\times 10^{3} / \mu \mathrm{l}\right)$ & $8.43 \pm 0.58$ & $7.31 \pm 0.61$ \\
Platelets $\left(\mathrm{x} 10^{5} / \mu \mathrm{l}\right)$ & $1.45 \pm 0.12$ & $1.43 \pm 0.10$ \\
Neutrophil $(\%)$ & $37.60 \pm 5.04$ & $40.40 \pm 5.75$ \\
Lymphocyte $(\%)$ & $60.80 \pm 4.87$ & $57.80 \pm 5.49$ \\
Eosinophil $(\%)$ & $0.40 \pm 024$ & $1.20 \pm 0.37$ \\
Monocyte $(\%)$ & $1.20 \pm 0.49$ & $1.40 \pm 0.40$
\end{tabular}




\section{Effect on Estrous Cycle}

Table 2 shows the effect of treatment of rats for 21 days with paracetamol on estrous cycle.

Treatment of rats for 21 days with paracetamol $(7.5 \mathrm{mg} / \mathrm{kg} \mathrm{BW})$ caused non-significant $(\mathrm{p}>0.05)$ changes in the duration of all the phases of estrous cycle relative to their respective controls.

Table 2: Effect of 21 days treatment of rats with paracetamol $(7.5 \mathrm{mg} / \mathrm{kg} \mathrm{BW})$ on estrous cycle $\left(\mathrm{n}=5,{ }^{*} \mathrm{p}<0.05\right)$

\begin{tabular}{lll}
\hline Phase & Control & Treated \\
\hline Proestrous & $4.60 \pm 0.23$ & $6.00 \pm 1.87$ \\
Estrous & $6.70 \pm 0.80$ & $5.80 \pm 1.46$ \\
Metestrous & $3.40 \pm 0.51$ & $3.00 \pm 0.63$ \\
Dietrous & $6.20 \pm 0.74$ & $6.20 \pm 1.32$ \\
\hline
\end{tabular}

\section{Discussion}

The values obtained for RBC showed the non-significant effect of treatment of rats with paracetamol on red blood cells (RBC) counts and indices relating to it ( $\mathrm{Hb}, \mathrm{PCV}, \mathrm{MCV}, \mathrm{MCH}$ and $\mathrm{MCHC}$ ) when compared with the control. This is an indication that there was no destruction of red blood cells and no change in the rate of production of RBC (erythropoiesis). This also shows that paracetamol does not has the potential to stimulate erythropoietin release from the kidneys, which is the humoral regulator of RBC production (Polenakovic and Sikole, 1996). The non-significant effect of treatment of rats with paracetamol also indicate that there were no change in the oxygen-carrying capacity of the blood and the amount of oxygen delivered to the tissues since RBC and haemoglobin (Hb) are very important in transferring respiratory gases (De Gruchy, 1976). It has been reported that values of RBC and associated parameters lower than normal ranges are indicative of anemic conditions while higher values are suggestive of polycythemia (American Diabetes Association, 2000), thus, the treatment of rats with paracetamol may not have the potential to induce anemia or polycythemia. Also, treatment of rats with paracetamol may not have adverse effects on the bone marrow, kidney and haemoglobin metabolism, since it has been reported that only substances which significantly affect the values of red blood cells and associated parameters would have effects on the bone marrow, kidney and haemoglobin metabolism (Young and Maciejewski, 1997).

Paracetamol caused non - significant changes in the MCV and MCH values which could be an indication of absence of macrocytic anaemia since increased $\mathrm{MCV}$ an $\mathrm{MCH}$ values are known to be indicative of macrocytic anaemia. Also, paracetamol caused non- significant change in the MCHC value which suggest and absence of hereditary spherocytosis since MCHC values are known to be elevated in hereditary spherocytosis.

The insignificant change in neutrophil count caused by paracetamol probably indicates that the ability of the body to attack and destroy invading bacteria, viruses and other injurious agents (Phagocytosis) has not been compromised. The non-significant change in lymphocyte count suggests that the acquired immune responses of the body has not been compromised by paracetamol; while the non- significant change in monocyte count probably indicates that the phagocytic function of the body has not been compromised by paracetamol. The non - significant change in eosinophil count probably indicates that the anti-allergic and anti-parasitic injections response of the body have not been compromised by paracetamol.

The insignificant change in TWBC count caused by paracetamol suggests that the immune system has not been compromised. Contrary report was given by Adewusi and Afolayan (2009) in Pelargonium reniforme extract treated rats. Also, the insignificant change in the platelet count caused by paracetamol could be an indication that it does not has the potential to stimulate thrombopoietin production ( $\mathrm{Li}$ et al., 1999) with the hemostatic capability of the blood maintaining the status quo since platelets mediate in the blood -clotting mechanism.

Treatment of rats for 21 days with paracetamol produced non-significant changes in the duration of all the phases of the estrous cycle compared to the control and this suggests that the drug did not cause an imbalance of the ovarian and extra-ovarian hormones, since it has been reported that imbalance in these hormones leads to irregularity in ovarian functions and duration of the estrous cycle (Circosta et al., 2001). Similar results were given by Oyedeji and Bolarinwa (2010) in Portulaca oleracea extracts treated rats.

These findings probably indicates that paracetamol has no deleterious effect on the blood chemistry and fertility of female albino rats. 


\section{REFERENCES}

[1] Al-Swayeh OA, Futter LE, Clifford RH, Moore PK (2000): Nitroparacetamol exhibits anti-inflammatory and anti-nociceptive activity. Br J Pharmacol 130 (7): 1453-1456.

[2] Anderson BJ, Holford NHG, Woollard GA (1998): Paracetamol plasma and cerebrospinal fluid pharmacokinetics in children. Br J Clin Pharmacol; 46: $237-43$

[3] Circosta C, Sanogo R, Occhiuto F (2001): Effect of Calotropis procera on estrous cycle and on estrogenic functionality in rats. Farmaco 2001; 56: $373-8$

[4] Dacie JV, Lewis SM (1991): Practical haematology, 7th edition ELBS with Churchill Livingston, England, pp $37-85$.

[5] Garcia RLA, Hernandez-Diaz S (2000): The risk of upper gastrointestinal complications associated with nonsteroidal antiinflammatory drugs, glucocorticoids, acetaminophen, and combinations of these agents. Arthritis Research and Theraphy 3 (2): 98 101.

[6] Hawkins LC, Edwards JN, Dargan PI (2007): Impact of restricting paracetamol pack sizes on paracetamol poisoning in the United Kingdom: a review of the literature. Drug Saf 30 (6): 465-79.

[7] Hongslo JK, Smith CV, Brunborg G. et. al., (1993): Genotoxicity of paracetamol in mice and rats. Mutagenesis 9 (2): $93-100$.

[8] Jain NC (1986): Schalm's Veterinary Haematology 4th ed. Lea and Fabiger, Philadelphia.

[9] Michael S, Gross AD, Altman R. (2007): The Cancer Dictionary. Infobase Publishing. ISBN 9780816064113.

[10] Mitruka BM, Rawnsley H (1977): Clinical, biochemical and haematological references values in normal experimental animals. Masson Publishing USA Inc. Pp. 53-54.

[11] Oyedeji KO, Bolarinwa AF (2010): Effects of extracts of Portulaca oleracea on reproductive functions in female albino rats Afr. J. Biomed. Res. 13

[12] Scottish Intercollegiate Guidelines Network (SIGN) (2008): Guideline 106: Control of pain in adults with cancer. Scotland: National Health Service (NHS).

[13] Ucheya RE, Igweh JC (2006): Histological changes in kidney structure following a long-term administration of paracetamol in pregnant Sprague Dawley rats. Nigeria Journal of Physiological Sciences 21(1-2): 77 - 81 . 